\title{
Plant Mediated Synthesis of Silver Nanoparticles and its Antibacterial Effect
}

\section{Shahnaz Majeed* and Muhammad Syahmi Bin Abdul Samad}

Faculty of Pharmacy and Health Sciences, Universiti Kuala Lumpur, Royal College of Medicine Perak Malaysia 30450, Malaysia.

\begin{abstract}
Aqueous extract of Clinacanthus nutans leaves were used as a biological source for the reduction of silver nitrate into silver nanoparticles. Result obtained from UV-Visible analysis exhibit the absorption peak at $460 \mathrm{~nm}$ confirms the production of silver nanoparticles. FTIR analysis showed the presence of alkyne, alcohol and primary amine that are responsible for reduction and stability of nanoparticles. The size of silver nanoparticles based on TEM analysis showed size from $6.26 \mathrm{~nm}$ until $26.77 \mathrm{~nm}$ and are in spherical shape. These nanoparticles showed good antibacterial activity and good synergistic effect in combination with different antibiotics such as amikacin, rifampicin, ofloxacin, moxifloxacin, piperacillin and levofloxacin against Escherichia coli, Klebsiella pneumonia and Staphylococcus epidermidis were studied.
\end{abstract}

Keywords: Silver nanoparticles, Clinacanthus nutans, UV-Visible, FTIR analysis TEM analysis, Antibacterial effect.

\footnotetext{
*Correspondence: shahnazsajeed5@gmail.com

(Received: 10 May 2019; accepted: 16 June 2019)
}

Citation: Shahnaz Majeed and Muhammad Syahmi Bin Abdul Samad, Plant Mediated Synthesis of Silver Nanoparticles and its Antibacterial Effect, J Pure Appl Microbiol., 2019; 13(2):1267-1272. doi: 10.22207/JPAM.13.2.69

(c) The Author(s) 2019. Open Access. This article is distributed under the terms of the Creative Commons Attribution 4.0 International License which permits unrestricted use, sharing, distribution, and reproduction in any medium, provided you give appropriate credit to the original author(s) and the source, provide a link to the Creative Commons license, and indicate if changes were made. 


\section{INTRODUCTION}

Nanotechnology is an important study that deals with strategy, synthesis and manipulation of matter at nanoscale size within the range of 1 to 100 nanometres which covers all aspects in biology, chemistry, physics, science and engineering. The principles of nano-technology are now widely applied in mechanic, cosmetics, biomedical, drug-gene delivery, environment, health, chemical industries as well as in nanomedicine. The overwhelming progress of nanotechnology field leads to the founding and development of diverse nanoparticles such as copper, titanium, zinc, magnesium, gold, alginate and silver (Logeswari et al., 2015). Nanoparticles unique physicochemical features such as nanoscale size which encompass one or more dimension with $100 \mathrm{~nm}$ or less, large surface area, chemically reactive and optically active (Khan et al., 2017) as well as antimicrobial and cytotoxic characteristics (Premasudha et al.,

Table 1. Zone of inhibition for combination of antibiotic with and without AgNPs against selected pathogen

\begin{tabular}{|c|c|c|c|c|}
\hline $\begin{array}{l}\text { Pathogen } \\
\text { Antibiotics }\end{array}$ & & $\begin{array}{c}\text { S. } \\
\text { epidermidis }\end{array}$ & $\begin{array}{l}E . \\
\text { coli }\end{array}$ & $\begin{array}{c}K . \\
\text { pneumonia }\end{array}$ \\
\hline & 1 & $10 \mathrm{~mm}$ & $27 \mathrm{~mm}$ & $26 \mathrm{~mm}$ \\
\hline \multirow[t]{2}{*}{ Piperacillin } & $1 a$ & $13 \mathrm{~mm}$ & $28 \mathrm{~mm}$ & $27 \mathrm{~mm}$ \\
\hline & 2 & $28 \mathrm{~mm}$ & $35 \mathrm{~mm}$ & $30 \mathrm{~mm}$ \\
\hline \multirow[t]{2}{*}{ Levofloxacin } & $2 a$ & $28 \mathrm{~mm}$ & $35 \mathrm{~mm}$ & $32 \mathrm{~mm}$ \\
\hline & 3 & $26 \mathrm{~mm}$ & $26 \mathrm{~mm}$ & $23 \mathrm{~mm}$ \\
\hline \multirow[t]{2}{*}{ Amikacin } & $3 a$ & $28 \mathrm{~mm}$ & $28 \mathrm{~mm}$ & $25 \mathrm{~mm}$ \\
\hline & 4 & $14 \mathrm{~mm}$ & $15 \mathrm{~mm}$ & $9 \mathrm{~mm}$ \\
\hline \multirow[t]{2}{*}{ Rifampin } & $4 a$ & $15 \mathrm{~mm}$ & $15 \mathrm{~mm}$ & $12 \mathrm{~mm}$ \\
\hline & 5 & $24 \mathrm{~mm}$ & $30 \mathrm{~mm}$ & $30 \mathrm{~mm}$ \\
\hline \multirow[t]{2}{*}{ Ofloxacin } & $5 a$ & $26 \mathrm{~mm}$ & $31 \mathrm{~mm}$ & $30 \mathrm{~mm}$ \\
\hline & 6 & $26 \mathrm{~mm}$ & $30 \mathrm{~mm}$ & $28 \mathrm{~mm}$ \\
\hline Moxifloxacin & $6 a$ & $27 \mathrm{~mm}$ & $31 \mathrm{~mm}$ & $29 \mathrm{~mm}$ \\
\hline $\mathrm{A}(\mathrm{AgNP})$ & & $14 \mathrm{~mm}$ & $16 \mathrm{~mm}$ & $14 \mathrm{~mm}$ \\
\hline
\end{tabular}

2015) truly attract significant interest not only in research area but also in medicine and health care area.

Among various nanoparticles, silver nanoparticles nowadays are more likely to be extensively used in catalysis, chemical sensing, electronics, and especially in pharmaceuticals due to their capability in antimicrobial activity. Silver products are known to possess great bactericidal and inhibitory effect because of its broad spectrum of antimicrobial activities (Krithiga et al., 2015) and does not exhibit any dangerous effects towards the body at low concentration (Theivasanthi \& Alagar, 2011).

Clinacanthus nutans locally known as Sabah snake plant or Belalai gajah in Malaysia. It is a type of medicinal plant where it is commonly be used in traditional treatment especially in Malaysia, Thailand and Indonesia (Alam et al., 2016). It possess anti-inflammation and anti-microbial activities whereby it is widely used for burns, fever, herpes skin infection and envenomation. It contains good percentage of fatty acid, minerals, and carbohydrate, and crude protein, essential and nonessential amino acids. Furthermore, $C$. nutans also has antibacterial properties to fight against pathogens which is used to treat skin infection such as acne (Yang et al., 2013). Plant leaves extract are used to synthesis silver nanoparticle as less cost is needed as it does not need any special preparation or isolation method (Alhamdani, 2016).

This study focused on the biosynthesis of silver nanoparticles from $C$. nutans leaves extract. Characterization of silver nanoparticles were conducted by using UV-spectrometer analysis, TEM analysis and FTIR analysis. These nanoparticles were further analysed for its antibacterial effect against various pathogens
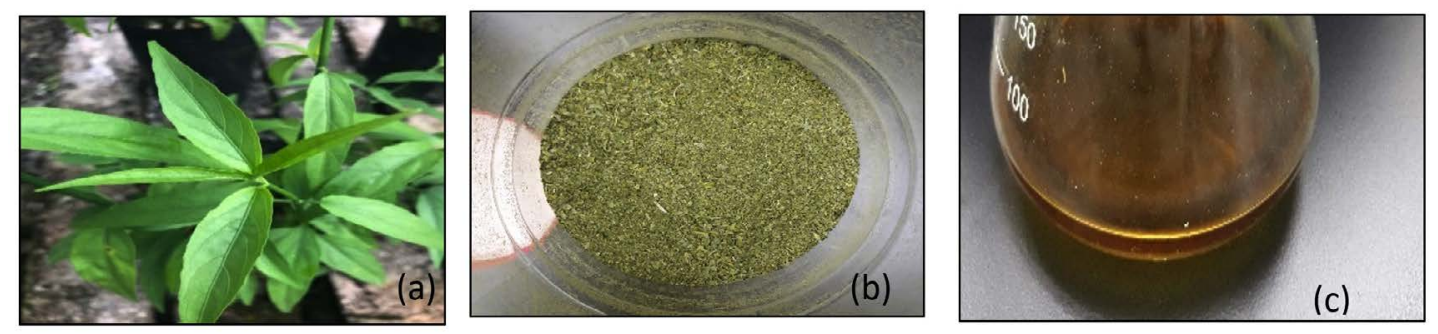

Fig. 1. (a) C. nutans plant (b) grinded leaves of $C$. nutans (c) silver nanoparticles 
and its synergistic effect with different antibiotics available in the market.

\section{MATERIALS AND METHODS \\ Collection of Plant}

Fresh leaves of $C$. nutans were collected from Taman Herba Perak, Malaysia in the month of January 2018. Authentication of the plant was conducted with the help of botanist from Taman Herba Perak.

\section{Preparation of plant extract}

Fresh leaves of $C$. nutans were washed and rinsed with running tap water for several times to remove dirt, dust particles and contamination from the leaves. Then, drying process of the leaves were carried out under the sun light for $10-15$ days to ensure all the moistures in the leaves completely removed. Dried leaves were ground to produce fine powder form by using a grinder machine prepared by UniKL RCMP laboratory. Later, 2 grams of plant powder sample was mixed and dissolved in $200 \mathrm{ml}$ of distilled water in 250 $\mathrm{ml}$ conical flask. Then the mixture was boiled to $100^{\circ} \mathrm{C}$ on hot plate for 10 minutes. The aqueous extract was let to cool down and followed with double filtration by using filter paper. The extract was collected and kept in conical flask to be used in the next session.

\section{Biosynthesis of silver nanoparticles}

$1 \mathrm{mM}$ of silver nitrate was used to synthesis silver nanoparticles. $1 \mathrm{mM}$ silver nitrate was mixed with $90 \mathrm{~mL}$ of water and $10 \mathrm{~mL} C$. nutans extract was added into the solution. The mixture was kept in a conical flask and mouth of

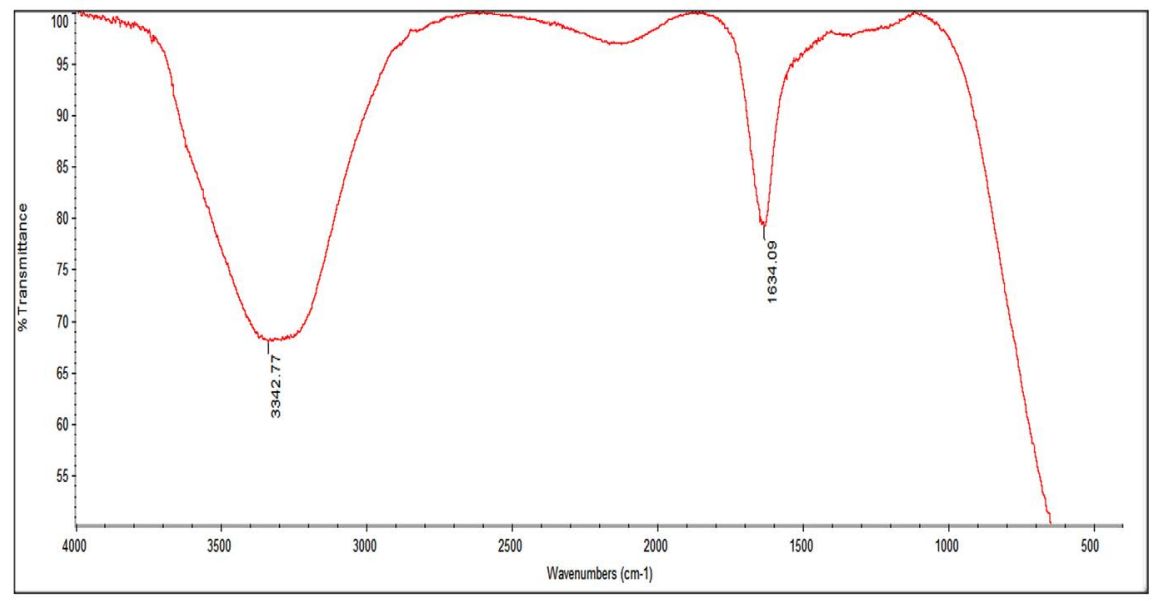

Fig. 2. FTIR spectra of AgNPs

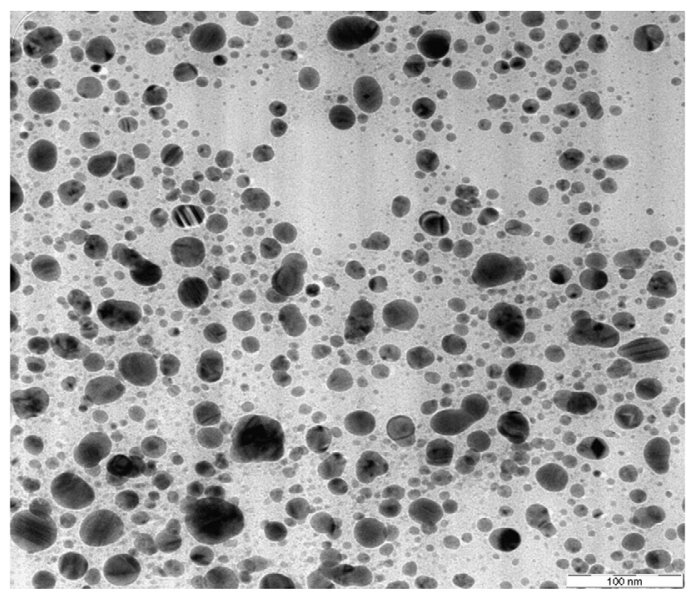

conical flask was covered with aluminium foil. It was kept for 24 hours on rotary shaker at 130rpm. The colour of mixture was changed which indicates the formation of silver nanoparticles. .

\section{Characterization of silver nanoparticles}

$1 \mathrm{ml}$ of sample was poured into the cuvette and observed for lamda max to determine the absorption by spectrophotometry from 300nm until 600nm. For FTIR powderd sample was used to determine the molecules and functional groups associated with the nanoparticle. For FTIR, sample was analysed along with potassium bromide and observed for the spectra from the region of $4000 \mathrm{~cm}^{-1}$ to $400 \mathrm{~cm}^{-1}$.

Fig. 3. TEM analysis of synthesized AgNPs 
TEM analysis was used to determine the particle size, shape and dispersity of the silver nanoparticles For TEM analysis sample was first sonication for 5 minutes and one drop of sample was poured on the copper coated grid and observed for TEM analysis.

\section{Antibacterial analysis}

Biologically synthesized silver nanoparticles were evaluated for tis antibacterial effect against E. coli, S. enterica and S. epidermidis on nutrient agar media by using disc diffusion method. Each disc was impregnated with $40 \mu \mathrm{g} /$ $\mathrm{ml}$ nanoparticles and compared with different antibiotics. All plates were incubated overnight for 24 hours at $37^{\circ} \mathrm{C}$. After 24 hours of incubation, the inhibition zone of each plate were measured and recorded in millimetre $(\mathrm{mm})$ unit

Synergistic effect of nanoparticles with antibiotics

Synergistic test was conducted to evaluate the synergistic effect of silver nanoparticles with combination of six antibiotics such as amikacin, rifampicin, ofloxacin, moxi-floxacin, piperacillin and levofloxacin. Prepared nutrient agar plate were swabbed with 4 different bacteria culture which were.E. coli, K. pneumonia and S. epidermidis and zone of inhibiton was measured after overnight incubation.

\section{RESULTS AND DISCUSSION}

C. nutans leaves extract were utilized for the biosynthesis of silver nanoparticles. The colour change of the solution after the addition of $1 \mathrm{mM}$ silver nitrate indicates the formation of silver nanoaprticles due to the excitation of surface plasmon resonance as shown in Fig. 1 (Ahmed et al., 2016) while UV spectrophotometric showed the absorption peak $460 \mathrm{~nm}$ confirms the formation.

Fourier-Transmission Infrared (FTIR) analysis was conducted to determine the possible
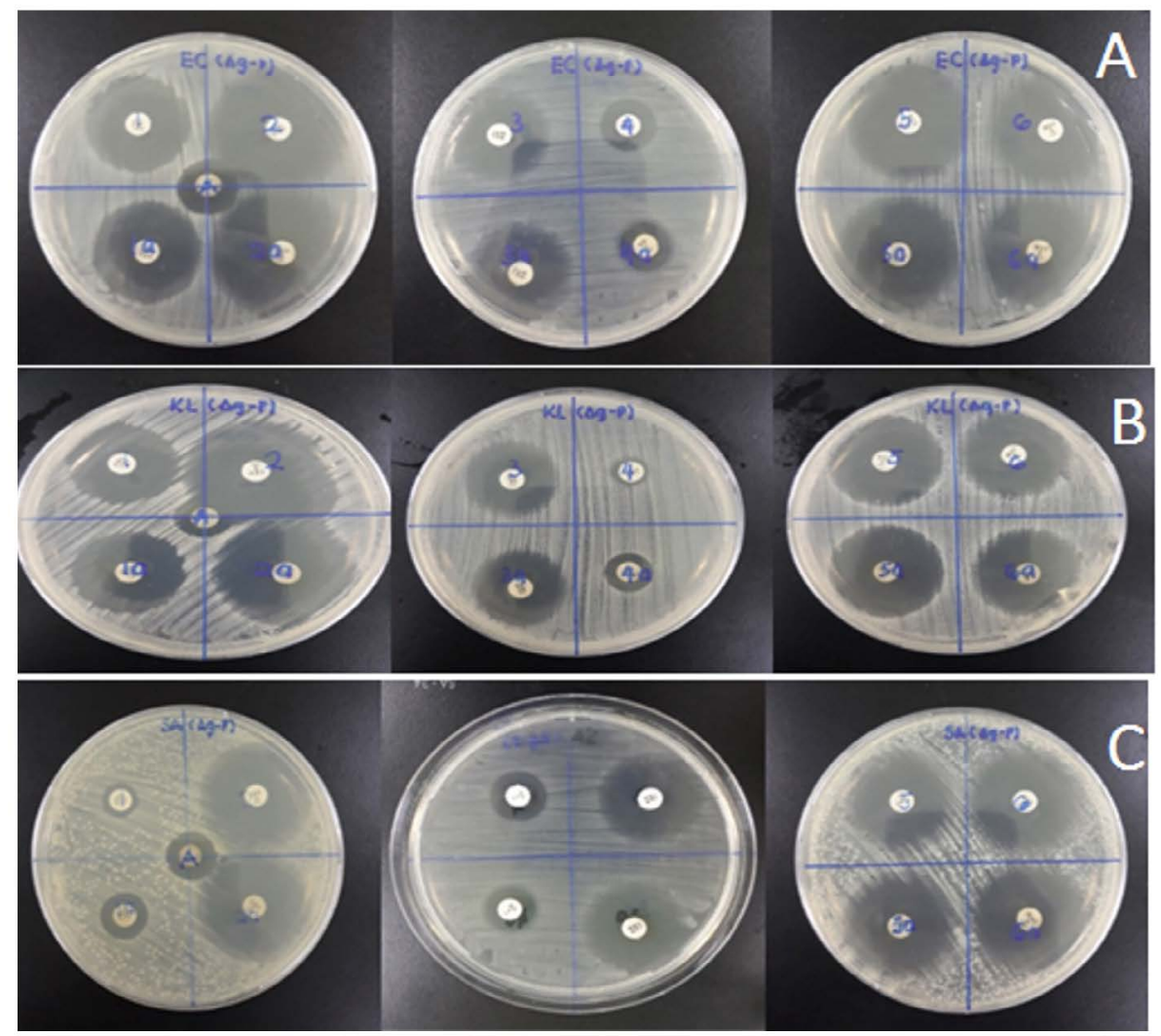

Fig 4. Zone of inhibition comparison between antibiotic with and without AgNPs samples (a) E.coli (b) Klebsiella pneumonia (c) Staphylococcus epidermidis 
functional group and biomolecules that are responsible for the stability of nanoparticles, reduction of the $\mathrm{Ag}^{+}$by plant extract and also capping of synthesized silver nanoparticles. The FTIR spectrum of silver nanoparticles showed absorption peaks in the range of 3500-1500 $\mathrm{cm}^{-1}$. The broad peak $3342.77 \mathrm{~cm}^{-1}$ indicated O-H stretch. The peak at $2100 \mathrm{~cm}^{-1}$ probably shows the presence of alkyne $(\mathrm{C}=\mathrm{C})$ compound. The absorption peak at $1634.09 \mathrm{~cm}^{-1}$ corresponded to $\mathrm{N}-\mathrm{H}$ bond of primary amine (Fig 2).

TEM analysis was conducted to determine the morphology, shape and size of the synthesized silver nanoparticles. Based on the analysis, spherical shape of particles are formed. Shape of nanoparticles is important for anti-bacterial activity (Rai et al., 2009). TEM image of silver nanoparticles shows the size of particles ranges from $6.26 \mathrm{~nm}$ until $26.77 \mathrm{~nm}$. Small size of silver nanoparticles will have better anti-microbial property as they have better contact with the bacteria due to their large surface area (Rai et al., 2009).

Antibacterial activity of silver nanoparticles was conducted against gram positive Escherichia coli and $K$. pneumonia and gram negative bacteria $S$. epidermidis. Evaluation test was conducted through disc diffusion method where each disc contained was impregnated with $40 \mu \mathrm{g} /$ disc of plant extract and silver nanoparticles. These nanoparticles showed good antibacterial effect against Staphylococcus epidermidis $22 \mathrm{~mm}$, E.coli $2 \mathrm{~mm}$ followed by K. pneumonia $19 \mathrm{~mm}$ zone of inhibition.

For synergistic test, sample of synthesized silver nanoparticles were analysed with six different antibiotics such as piperacillin, amikacin, ofloxacin, moxifloxacin, levofloxacin and rifampin. These combination were tested against three bacteria pathogens such as S. epidermidis, E. coli, and K.pneumonia to evaluate their synergistic effect. The inhibition zone of each plate were recorded as stated in the table 1 . Antibacterial activity of piperacillin was slightly improved in the presence of AgNPs as the size of inhibition zone increase Combination of levofloxacin with AgNPs does not showed improvement in antibacterial activity against $S$. epidermidis. Antibacterial activity of amikacin with AgNPs against the three pathogenic bacteria exhibited an improvement as the size of inhibition zone for each disc increase compared to blank antibiotic disc. This showed the presence of AgNPs has synergistic effect on antibacterial activity of amikacin. Combination of AgNPs with rifampin also increases the antibacterial properties of rifampin except against $E$. coli strain. Combination of AgNPs with moxifloxacin increases the antibacterial activity of the antibiotic, indicating the exhibition of synergistic effect of AgNPs. But for ofloxacin, no synergistic effect in term of ofloxacin antibacterial activity against $K$. pneumonia even in the presence of AgNPs (Fig. 4).

Mechanisms of antibacterial effect AgNPs is not well known. First possible mechanism is AgNPs interrupt the permeability and respiration of the cell by attaching to surface membrane of bacteria. AgNPs also cause plasmolysis of cell wall where the cytoplasm of the cell detach from the cell wall and inhibit synthesis of bacteria cell wall (Guzman et al., 2015). Production of free radicals from silver metal will initiate oxidative stress which can contribute to damage of DNA, membrane and mitochondria of bacteria. This can lead to cell death (Tippayawat et al., 2016).

\section{CONCLUSION}

Silver nanoparticles synthesized from Clinacanthus nutans exhibit good antibacterial activity and shows good synergistic effects against selected pathogenic bacteria. Bio-synthesis of nanoparticles by using Clinacanthus nutans extract is a success and better than physical and chemical synthesis as it is cost effective and safe to environment. Synergistic effect of silver nanoparticle towards selected antibiotic such as piperacillin, amikacin, ofloxacin, moxifloxacin, levofloxacin and rifampin exhibit positive result as nanoparticles manage to enhance the bactericidal properties of the antibiotics

\section{ACKNOWLEDGEMENTS}

None.

\section{CONFLICT OF INTEREST}

The authors declare that there is no conflict of interest. 


\section{AUTHORS' CONTRIBUTION}

All authors have made substantial, direct and intellectual contribution to the work and approved it for publication.

\section{FUNDING}

None

\section{DATA AVAILABILITY}

All datasets generated or analyzed during this study are included in the manuscript.

\section{ETHICS STATEMENT}

This article does not contain any studies with human participants or animals performed by any of the authors.

\section{REFERENCES}

1. Ahmed S., Ahmad M., Swami B.L. \& Ikram S. A review on plants extract mediated synthesis of silver nanoparticles for antimicrobial applications: A green expertise. Journal of Advanced Research, 2016; 7(1): $17-28$.
2. Alam A., Ferdosh S., Ghafoor K., Hakim A., Juraimi A.S., Khatib A. \& Sarker Z.I. Clinacanthus nutans: A review of the medicinal uses, pharmacology and phytochemistry. Asian Pacific Journal of Tropical Medicine, 2016; 9(4): 402-409.

3. Alhamdani A.H. Synthesis of silver nanoparticles, (January 2014), 2016.

4. Guzman M., Dille J. \& Godet S. Synthesis and antibacterial activity of silver nanoparticles against gram-positive and gram-negative bacteria. Nanomedicine: Nanotechnology, Biology and Medicine, 2015; 8(1): 37-45.

5. Khan I., Saeed K. \& Khan I. Nanoparticles/: Properties, applications and toxicities. Arabian Journal of Chemistry, 2017,

6. Krithiga, N., Rajalakshmi, A., \& Jayachitra, A. Green Synthesis of Silver Nanoparticles Using Leaf Extracts of Clitoria ternatea and Solanum nigrum and Study of Its Antibacterial Effect against Common Nosocomial Pathogens, 2015.

7. Logeswari P., Silambarasan S. \& Abraham J. Synthesis of silver nanoparticles using plants extract and analysis of their antimicrobial property. Journal of Saudi Chemical Society, 2015; 19(3): 311-317.

8. Theivasanthi T. \& Alagar M. Anti-bacterial Studies of Silver Nanoparticles. arXiv, 2011; 1101(348): 5. 